\title{
Empirical Validation of the Team Work Engagement Construct
}

\author{
Patrícia Costa, ${ }^{1}$ Ana Margarida Passos, ${ }^{1}$ and Arnold Bakker ${ }^{2}$ \\ ${ }^{1}$ Instituto Universitário de Lisboa - ISCTE-IUL, Lisbon, Portugal, ²Erasmus University, \\ Rotterdam, The Netherlands
}

\begin{abstract}
This article presents an empirical validation of the construct of team work engagement. Two different samples were used to test the hypotheses. Results from convergent and discriminant validity are presented as well as confirmatory factor analysis that explores the construct's factor structure. Results support the idea that team- and individual-level work engagement are two different, yet related, constructs. However, data do not support the factorial invariance across levels: At the team level, the 1-factor structure, and not the 3-factor one, seems to be the one that best fits the data. This is a necessary first step for future research providing a justification for further analyzing the importance of team work engagement and its relationship with other variables, namely with team effectiveness.
\end{abstract}

Keywords: team work engagement, collective constructs, confirmatory factor analysis, validation

A rich body of literature from the last decade has converged on the relevance of the relationship between work engagement (WE) and individual performance and well-being (e.g., Halbesleben, 2010; Schaufeli \& Bakker, 2003). It is also well acknowledged that job resources (e.g., autonomy, feedback) facilitate the development of WE and buffer the negative effects of job demands such as rapid work pace and inefficient equipment (Bakker \& Demerouti, 2007). Most of the studies on WE were conducted at the individual level. However, many people work in teams and need to interact with others in order to perform their tasks. Do the specific dynamics of working within a group of people collectively impact the levels of energy and motivation of employees? In this article we investigate whether team work engagement (TWE) exists as a construct that is qualitatively different from work engagement at the individual level. We expect that the two constructs are related, yet different. This paper may contribute to the literature in two ways. First, although TWE has been used in previous studies (e.g., Bakker, Van Emmerik, \& Euwema, 2006; Salanova, Llorens, Cifre, Martinez, \& Schaufeli, 2003; Torrente, Salanova, Llorens, \& Schaufeli, 2012a, 2012b) it is still unknown whether it is empirically distinct from individual WE. Second, as a methodological contribution, this study proposes a different operationalization of TWE, measuring it as a team property (by using "we" as the referent of the items). Finally, we compare two methods for measuring collective constructs: The aggregation of individual answers and a single score obtained through group discussion.

\section{Team Work Engagement}

Work engagement is defined as a positive, fulfilling, workrelated state of mind characterized by vigor, dedication, and absorption (Schaufeli, Salanova, González-Romá, \& Bakker, 2002). Work engaged employees tend to be energetic and enthusiastic about their work and it impacts on both their task and extra-role performance (e.g., Halbesleben \& Wheeler, 2008). Therefore, engaged workers not only perform better than nonengaged ones, but they are also more willing to make more effort than what is expected of them. One of the psychological mechanisms underlying the engagement-performance link is the experience of positive emotions by employees. According to the broaden-and-build theory (Fredrickson, 2001), experiencing positive emotions results in a momentary broadening of peoples' thought-action repertoires and in an overtime building of resources (physical, social cognitive, and psychological). For example, when one experiences interest, he or she will feel the desire to explore and learn.

Work engagement is likely to collectively exist in teams. Previous research has showed that people working together present similar patterns of mood. For example, Totterdel, Kellett, Teuchmann, and Briner (1998) found a significant association between the mood of 65 community nurses and their teammates, which was independent from shared daily hassles. They also found the same pattern with a sample of accountants. This affect similarity may be due to emotional contagion (Hatfield, Cacioppo, \& Rapson, 1994). In teams, individuals are able to perceive and 


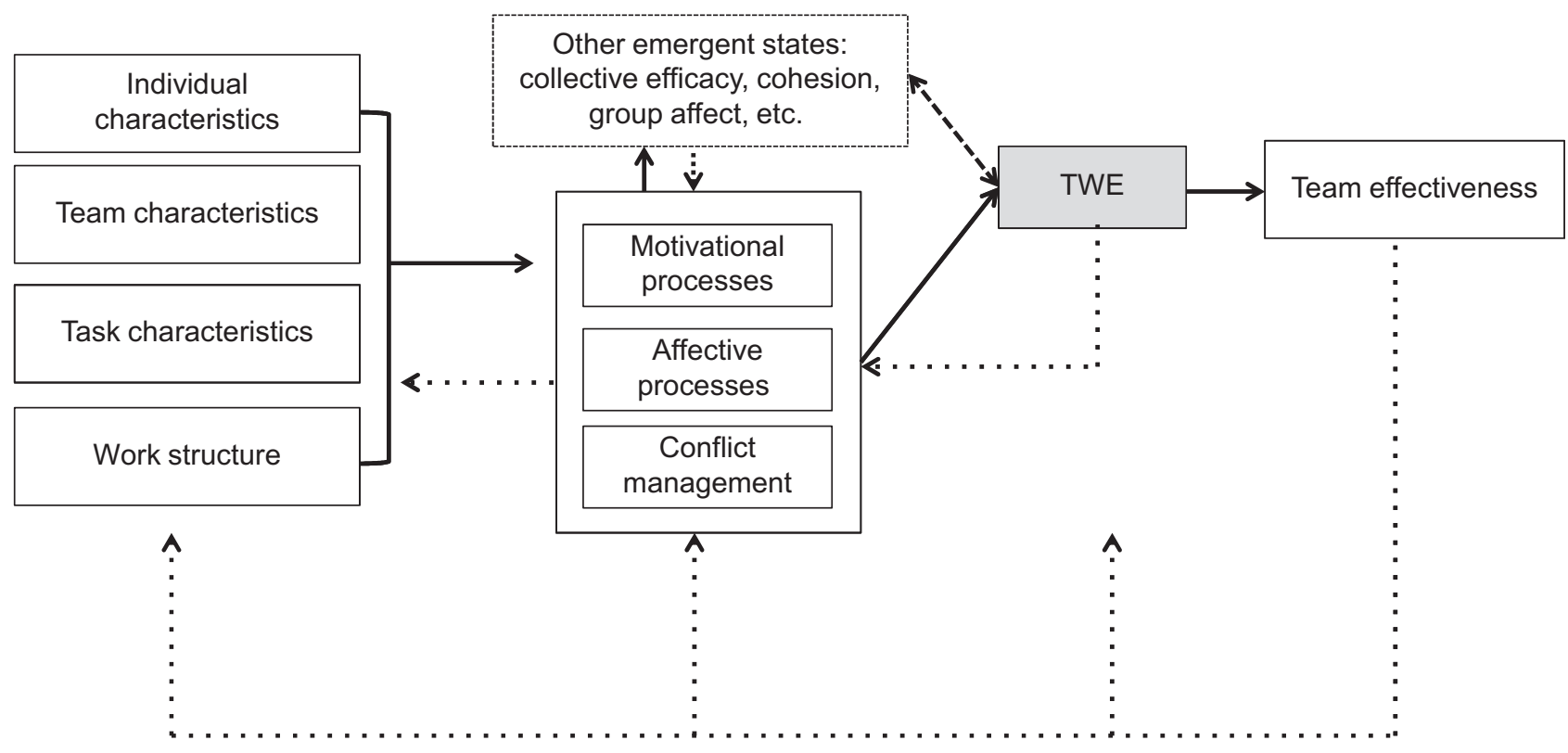

Figure 1. Model for the emergence of team work engagement (adapted from Costa, Passos, \& Bakker, 2012). Solid arrows represent direct effects. Dashed arrows represent correlations. Dotted arrows represent feedback loops.

observe the behavior of their coworkers. Team members can see, for example, that one of their colleagues is enthusiastic about a new project because he is smiling when talking about it, uses a higher tone of voice and gestures a lot. At the same time, they can listen to another coworker complaining about how boring their tasks are and catch her drawing absently in the corner of her sheets during a meeting. Emotional contagion is based on the transmission of nonverbal signs of emotion (tone of voice, facial expressiveness, and tempo of discourse), that are automatically and subconsciously reproduced by the other, that ends by experiencing similar emotional states. In teams, when people interact on a regular basis, there are frequent opportunities for this to happen. Moreover, people can openly and explicitly tell other how they are feeling toward work.

TWE is, then, a shared, positive, fulfilling, motivational emergent state of work-related well-being (Costa, Passos, $\&$ Bakker, 2012). It is shared because, to state the existence of team level WE, team members must have similar perceptions of this state. If team members have high variability in their perceptions of the level of engagement of their team, then we can only talk about a team member's individual perceptions of his/her team's level of engagement and not of TWE. TWE is considered an emergent state whose collective structure is shaped by the nature of their members' interactions during team processes and dynamics. For example, enthusiastic comments about a new prospective client by one team member who incites coworkers to actively suggest strategies to promote its loyalty are likely to foster the emergence of TWE. Also, reviewing the previous years' sales results in a gloomy tone of voice and passively charging the "economical situation" will tend to hinder the energy and enthusiasm of the team.
Teams develop a certain level of collective engagement as a consequence of a specific configuration of inputs (previous performance, work structure, leader's behavior, work events, and so on) and of team processes (e.g., mission analysis, planning, coordination), particularly interpersonal processes (motivation, conflict, and affect management) (see Figure 1). Work engaged teams tend to collectively display positive emotions while working, such as enjoyment and pride, and to be actively involved in team processes (Marks, Mathieu, \& Zaccaro, 2001). A high level of TWE leads teams to invest time and effort in planning and goal setting, coordinating the sequence and timing of activities, in tracking team resources, and in proving backup responses (such as assisting team members to perform their tasks, by providing verbal feedback or coaching). Members of work engaged teams also invest in regulating members' emotions, adequate conflict management, and confidence building, according to their positive affective state.

\section{TWE and Related Variables}

Establishing TWE as an independent construct implies theoretically defining its relationships with relevant constructs in order to assess its convergent and discriminant validity. Here, we discuss some team-level and individual-level variables that have been studied as related both to performance and well-being at work, highlighting their possible relationship with TWE. All of these variables may be related to both TWE and WE. However, team-level variables are likely to have a relationship of greater magnitude with TWE, since it is defined as an emergent state. As such, it is dependent on the interaction and dynamics that occur 
within the team and not so much on individual characteristics. At the same time, individual-level variables are likely to show relationships of greater magnitude with WE, since they both pertain to the individuals singly.

The team level variables are collective efficacy, team potency, identification with the team, and relational conflict (Study 1), and team viability (Study 2).

Collective efficacy is a group's shared belief that they can execute their tasks successfully (Bandura, 1997). Whereas collective efficacy has a specific temporal focus and is sensitive to specific situations, team potency generalizes the belief to "any task or demand a group may confront," and has an enduring temporal focus and broad outcome emphasis (Stajkovic, Lee, \& Nyberg, 2009). These variables are most likely connected to TWE. When I believe my team is able to attain a certain goal, I probably experience work-related well-being. Indeed, they might reinforce each other. However, whereas collective efficacy and team potency have a cognitive nature (are defined as believes), TWE implies an affective well-being and a drive to act in benefit of the team. Both collective efficacy (Bandura, 1997) and group potency (Guzzo, Yost, Campbell, \& Shea 1993) are thought to be positively correlated with TWE. At the individual level, self-efficacy is one of the personal resources that work as an input for work engagement (Bakker \& Leiter, 2010), and we expect that, at the team level, the two engagement constructs have a certain degree of isomorphism.

Identification with the team implies thinking about oneself as a group member and it drives from the relationships the individual establishes as a member of the group and from the value and emotional significance that membership has to the individual (Tajfel \& Turner, 1986). Identifying with the work group is related to a greater commitment to the group, cohesion, altruism, positive evaluations of the group, and fewer withdrawal behaviors such as absenteeism, social loafing, and turnover (Riordan \& Weatherly, 1999). Therefore, TWE is expected to positively correlate to identification with the team.

Team viability is defined as a team's capacity for the sustainability and growth required for success in future performance episodes (Bell \& Marentette, 2011). Since TWE is characterized by positive affect within a team and by a high level of collective dedication to work, it is likely that in teams with high TWE, its members welcome the possibility for working together in the future, as well as their perceptions of room for development as a team. Considering engagement's relationship with performance at the individual level, it is also expected that TWE correlates positively with objective team performance.

Finally, we expect relational conflict to show a nonsignificant relationship with TWE. Although it has been demonstrated that both relationship and task conflict relate to team performance and team satisfaction (De Dreu \& Weingart, 2003), relationship conflict is about the personal relationships of team members, whereas work engagement is focused on the work itself.

At the individual level, we discuss burnout, job satisfaction, and subjective well-being.
Burnout (Maslach, 1999) is seen as the antipode of work engagement. It is defined as a negative three-dimensional syndrome, the components of which are: emotional exhaustion, depersonalization/cynicism, and reduced personal accomplishment. We expect TWE to be negatively correlated with the dimensions of emotional exhaustion and cynicism and positively correlated with the dimension of personal accomplishment of burnout.

Job satisfaction, a "pleasurable or positive emotional state resulting from the appraisal of one's job" (Locke, 1976, p. 1300), is also put forward as positively correlated with TWE, since both reflect a positive emotional state related to work.

Subjective well-being, how individuals evaluate their lives, both in terms of satisfaction judgments and in terms of affective reactions (moods and emotions) (Diener, 1994) is also expected to be correlated with TWE, since emotional states at work may spill over to other areas of life and contribute to a higher or lower general well-being.

\section{The Present Study}

The different elements of the definition of WE, both at the individual and at the team level, suggest that these constructs are different concerning their structure. Should this be true, it would be possible to find individuals who have a high level of individual WE, but who work in a team that has a lower level of TWE, or someone who belongs to a highly work engaged team while his/her individual levels of motivation and/or energy are low. These differences can be captured if researchers operationalize WE differently at both levels, by measuring TWE as a team property and individual work engagement as an individual property. If significant differences are found in the responses to those measures, then we can infer that individual work engagement and TWE, despite the fact of probably being correlated, reflect two distinct constructs.

Hypothesis 1: The aggregated mean scores on the individual WE scale and on the TWE scale will be significantly different.

Three possibilities exist for collecting data on collective constructs: (1) the consensus model; (2) the referent-shift composition model (Chan, 1998; Chen, Bliese, \& Mathieu, 2005); and (3) a single holistic measure obtained through group discussion (Goddard, Hoy, \& Hoy, 2004). The main difference between the consensus and the referent-shift models is the construct's referent: In item formulation, consensus models ask individually focused items ("I..."), whereas referent-shift models refer to the collective in the measure ("We..."). We argue that if computing mean scores of individual-level WE using a consensus model the mean scores of a group would still refer to members' perceptions about themselves and not about the team, since those mean scores were obtained from individually focused items. Indeed, according to Chan (1998), "the change in the 
referent results in a new form of the original focal construct that is conceptually different from the original form" ( $\mathrm{p}$. 239). Therefore, we believe the consensus model is a fuzzy representative of the true collective construct and the mean scores of a group of individuals on collectively formulated items ("We...") is a better representation of it.

Bar-Tal (1990) posits that the origin of a shared belief depends on the interaction that occurs within the group. In accord with this idea and with the definition of an emergent stare, the measurement of a collective emergent state also should reflect that interaction process. In the group discussion process, team members decide together on the best answer for each item on a scale, resulting in a single score, as opposed to an aggregated one (e.g., Gibson, Randel, \& Earley, 2000).

We argue that both the reference-shift composition model and the holistic measure through group discussion are equally good possibilities for data collection on collective phenomena, including TWE. Since it is a shared state, team members must display similar perceptions.

Hypothesis 2: No significant differences exist between measuring TWE through the aggregation of individual scores using the referent-shift model and measuring it by a holistic measure reflecting the interaction between team members.

In order to demonstrate TWE's convergent and discriminant validity, we selected the variables presented above.

Hypothesis 3a: TWE is positively correlated with the dimension of personal accomplishment of burnout, job satisfaction, subjective well-being, identification with the team, team viability, objective team performance, collective efficacy, and group potency.

Hypothesis $3 b$ : TWE is negatively correlated with the dimensions of emotional exhaustion and cynicism of burnout.

Hypothesis 3c: TWE and relational conflict are not significantly correlated.

Hypothesis 3d: TWE has relationships of greater magnitude with team-related variables (collective efficacy, group potency, identification with the team, and team viability) whereas WE has relationships of greater magnitude with individual-level variables (subjective well-being, job satisfaction, and the three dimensions of burnout).

Finally, the present study aims at exploring whether the 3 -factor structure of work engagement found at the individual level (e.g., Schaufeli \& Bakker, 2003; Schaufeli, Bakker, \& Salanova, 2006) is maintained at the higher level of analysis. Following the proposed definition of TWE, it is expected that the 3 -factor structure will be maintained.
Hypothesis 4: The factor structure of TWE is similar to the one of individual-level work engagement and is composed by three factors: vigor, dedication, and absorption.

We conducted our analyses in two separate studies. In the first study, we addressed Hypotheses 1 to 3 (excluding the variables team viability and objective performance, analyzed in Study 2), and superficially explored Hypothesis 4 , using only one sample. On Study 2, we enriched the tests for convergent and discriminant validity, and tested the factorial structure at the team level with a larger sample in order to explore Hypothesis 4.

\section{Study 1}

\section{Method}

\section{Participants, Procedure, and Measures}

In this study 226 participants working in 55 teams filled out one questionnaire. Each team could be composed by undergraduate and graduate students doing an end of term group work $(n=126)$ that would answer the survey considering their work team at the University or by a mix of working students $(n=27)$ and full-time workers $(n=73)$. In these teams, one of the participants was a working student at the University who would bring his/her work team to answer the survey considering their work group at work. In all the cases all of the team members completed the survey. Most of the respondents were female $(74.7 \%)$ and under 25 years of age $(60.7 \%)$. Most of the teams had been working together for less than 6 months $(49.2 \%)$ and the average team size was 4.62 members $(S D=1.85)$.

After individually completing the individual surveys comprising all the variables of the study, teams were given the holistic measure of TWE to fill in together. They were told to decide together on the answer to each item that they thought best described their view as a team. We did not counterbalance the order of completion of the two different methods and all the teams completed the discussion method after individually answering the survey. This decision was indeed to make sure every member would have the opportunity to make up his/her mind and to be able to have a prior opinion to bring to the discussion, minimizing the possible impact of dominant members and, therefore, enhancing a "shared" response.

In Table 1 we present all of the measures used in both studies. The proposed measurement instrument for TWE is based on the content of the original, individual level, UWES items (Schaufeli et al., 2002). For conveying a collective/team positioning we focused on the subject of the sentence. Reflecting the reference-shift composition model (Chan, 1998) and Bar-Tal's (1990) ideas on group beliefs, we chose to use the first-person plural: According to linguistics (e.g., Cintra \& Cunha, 1984), when using the 
Table 1. Measures of Studies 1 and 2

\begin{tabular}{|c|c|c|c|c|c|}
\hline Study & Variable & Scale and source & $\begin{array}{l}\text { No. of } \\
\text { items }\end{array}$ & Item examples & $\begin{array}{l}\text { Cronbach's } \alpha \\
\text { (individual/ } \\
\text { aggregated) }\end{array}$ \\
\hline \multirow[t]{15}{*}{ Study 1} & \multirow[t]{3}{*}{$\begin{array}{l}\text { Individual work } \\
\text { engagement }\end{array}$} & $\begin{array}{l}\text { Utrecht work engagement } \\
\text { scale }\end{array}$ & & $\begin{array}{l}\text { Vigor: At my work, I feel } \\
\text { bursting with energy }\end{array}$ & $.80 / .86$ \\
\hline & & (Schaufeli et al., 2002) & 9 & $\begin{array}{l}\text { Dedication : I am proud of the } \\
\text { work that I do }\end{array}$ & $.83 / .91$ \\
\hline & & & & $\begin{array}{l}\text { Absorption : I get carried away } \\
\text { when I am working }\end{array}$ & $.74 / .83$ \\
\hline & \multirow[t]{3}{*}{$\begin{array}{l}\text { Team work } \\
\text { engagement }\end{array}$} & & & $\begin{array}{l}\text { Vigor: At our work, we feel } \\
\text { bursting with energy }\end{array}$ & $.85 / .88$ \\
\hline & & $\begin{array}{l}\text { Team work engagement } \\
\text { scale }\end{array}$ & 9 & $\begin{array}{l}\text { Dedication : We are proud of } \\
\text { the work that we do }\end{array}$ & $.88 / .89$ \\
\hline & & & & $\begin{array}{l}\text { Absorption : We get carried } \\
\text { away when we are working }\end{array}$ & $.83 / .82$ \\
\hline & Relational conflict & $\begin{array}{l}\text { Intragroup conflict scale } \\
\text { (Jehn \& Mannix, 2001) }\end{array}$ & 4 & $\begin{array}{l}\text { Are interpersonal conflicts } \\
\text { evident in the team? }\end{array}$ & $.88 / .92$ \\
\hline & \multirow[t]{3}{*}{ Burnout } & $\begin{array}{l}\text { Maslach burnout } \\
\text { inventory, general survey }\end{array}$ & & $\begin{array}{l}\text { Emotional exhaustion: } \\
\text { Working all day is really a } \\
\text { strain for me }\end{array}$ & $.88 / .92$ \\
\hline & & \multirow[t]{2}{*}{$\begin{array}{l}\text { (Maslach, Jackson, \& } \\
\text { Leiter, 1996) }\end{array}$} & \multirow[t]{2}{*}{17} & $\begin{array}{l}\text { Cynicism: I don't really care if } \\
\text { my work is well done or poorly }\end{array}$ & $.71 / .79$ \\
\hline & & & & $\begin{array}{l}\text { professional efficacy: At my } \\
\text { work, I am confident that I am } \\
\text { effective at getting things done }\end{array}$ & $.83 / .87$ \\
\hline & \multicolumn{2}{|l|}{ Job satisfaction } & 1 & $\begin{array}{l}\text { In general, and considering all } \\
\text { the aspects of your work, you } \\
\text { would say you are... }\end{array}$ & - \\
\hline & Group potency & Guzzo et al., 1993 & 8 & $\begin{array}{l}\text { No task is too difficult for my } \\
\text { team }\end{array}$ & $.90 / .94$ \\
\hline & $\begin{array}{l}\text { Collective } \\
\text { efficacy }\end{array}$ & Jex \& Bliese, 1999 & 5 & $\begin{array}{l}\text { My team has the necessary } \\
\text { skills to have good results in its } \\
\text { tasks }\end{array}$ & $.92 / .94$ \\
\hline & $\begin{array}{l}\text { Subjective well- } \\
\text { being }\end{array}$ & $\begin{array}{l}\text { Satisfaction with life scale } \\
\text { (Diener, Emmons, Larsen, } \\
\text { \& Griffin, 1985) }\end{array}$ & 5 & $\begin{array}{l}\text { In most ways my life is close to } \\
\text { my ideal }\end{array}$ & $.86 / .81$ \\
\hline & $\begin{array}{l}\text { Identification with } \\
\text { the team }\end{array}$ & $\begin{array}{l}\text { Doosje, Ellemers, and } \\
\text { Spears (1995) }\end{array}$ & 4 & $\begin{array}{l}\text { I see myself as a member of } \\
\text { my team }\end{array}$ & $.88 / .93$ \\
\hline \multirow[t]{5}{*}{ Study 2} & \multirow[t]{2}{*}{ Team viability } & \multirow[t]{2}{*}{$\begin{array}{l}\text { Standifer, Halbesleben, } \\
\text { and Kramer (2009), } \\
\text { adapted }\end{array}$} & 4 & $\begin{array}{l}\text { This team can perform well in } \\
\text { future projects }\end{array}$ & $.85 / .89$ \\
\hline & & & & $\begin{array}{l}\text { Vigor: At our work, we feel } \\
\text { bursting with energy }\end{array}$ & $.97 / .96$ \\
\hline & \multirow[t]{2}{*}{$\begin{array}{l}\text { Team work } \\
\text { engagement }\end{array}$} & \multirow{2}{*}{\multicolumn{2}{|c|}{$\begin{array}{l}\text { Team work engagement } \\
\text { scale }\end{array}$}} & $\begin{array}{l}\text { Dedication : We are proud of } \\
\text { the work that we do }\end{array}$ & $.95 / .94$ \\
\hline & & & & $\begin{array}{l}\text { Absorption : We get carried } \\
\text { away when we are working }\end{array}$ & $.95 / .87$ \\
\hline & $\begin{array}{l}\text { Objective team } \\
\text { performance }\end{array}$ & \multicolumn{4}{|c|}{$\begin{array}{l}\text { Computation of the difference between the companies' stock market share prices at the } \\
\text { beginning of the competition (week 1) and the value achieved at the end (week 5) was } \\
\text { computed. This generated a team performance index for the companies' stock marketshare } \\
\text { price. }\end{array}$} \\
\hline
\end{tabular}

first-person plural ("we") the speaker includes him- or herself in the group that is being described more strongly than when using a more neutral formulation such as "the team." We chose to reinforce the idea of individual belongingness to the group by using first-person plural pronouns ("we," "our," "us"). We believe that the use of these pro- nouns also helps the respondents to focus on the team and not on individual work that may not be relevant for them collectively.

The only content change made to the original UWES scale was in item 8 ("When I get up in the morning, I feel like going to work"), a clearly individual item with no 
Table 2. Means, standard deviations, correlations, Rwgs, and ICCs for all the variables in the study

\begin{tabular}{|c|c|c|c|c|c|c|c|c|c|c|c|c|c|c|c|c|}
\hline & Rwg & ICC1 & ICC2 & M & $S D$ & 2 & 3 & 4 & 5 & 6 & 7 & 8 & 9 & 10 & 11 & 12 \\
\hline 1.UWES9 & .89 & .32 & .80 & 4.7 & .67 & $1.88^{* *}$ & $.73^{* *}$ & $.66^{* *}$ & $-.61^{* *}$ & $-.70^{* *}$ & $.29^{*}$ & $.38^{*}$ & $.34^{*}$ & $.44^{* *}$ & $.50^{* *}$ & -.18 \\
\hline 2. TWES9 & .87 & .19 & .57 & 4.8 & .63 & 1 & $.74^{* *}$ & $.69^{* *}$ & $-.58^{* *}$ & $-.59^{* *}$ & $.43^{* *}$ & $.28^{*}$ & $.48^{* *}$ & $.61^{* *}$ & $.63^{* *}$ & -.21 \\
\hline 3. TWES9-HM & - & - & - & 4.8 & 1.0 & & 1 & $.58^{* *}$ & $-.55^{* *}$ & $-.52^{* *}$ & $.35^{*}$ & $.34^{*}$ & $.34^{*}$ & $.46^{* * *}$ & $.54^{* *}$ & -.13 \\
\hline 4. MBI-PE & .86 & .23 & .63 & 5.6 & .64 & & & 1 & $-.38^{*}$ & $-.38^{*}$ & .15 & $.32^{*}$ & $.33^{*}$ & $.34^{*}$ & $.50^{* *}$ & -.02 \\
\hline 5. MBI-EE & .73 & .27 & .68 & 3.8 & .98 & & & & 1 & $.74^{* *}$ & -.22 & .18 & -.18 & $-.36^{*}$ & $-.32^{*}$ & .18 \\
\hline 6. MBI-CY & .78 & .24 & .64 & 3.1 & .82 & & & & & 1 & -.19 & -.23 & -.18 & -.24 & -.20 & .16 \\
\hline 7. Job. Satisf & .77 & .17 & .53 & 5.3 & .68 & & & & & & 1 & .17 & $.58^{* *}$ & $.63^{* *}$ & $.52^{* *}$ & $-.46^{* *}$ \\
\hline 8. Sub. well-being & .77 & -.02 &.-09 & 5.0 & .48 & & & & & & & 1 & .26 & .19 & $.32^{*}$ & -.02 \\
\hline 9. Identification & .87 & .26 & .66 & 5.8 & .65 & & & & & & & & 1 & $.82^{* *}$ & $.78^{* *}$ & $-.42^{*}$ \\
\hline 10. Collective efficacy & .86 & .16 & .52 & 5.8 & .59 & & & & & & & & & 1 & $.80^{* *}$ & $-.50^{* *}$ \\
\hline 11. Group potency & .88 & .21 & .59 & 5.56 & & & & & & & & & & & 1 & -.26 \\
\hline 12. Rel. conflict & .83 & .32 & .73 & 2.2 & .81 & & & & & & & & & & & 1 \\
\hline
\end{tabular}

Notes. ${ }^{*}$ Correlation is significant at the 0.05 level (2-tailed). ${ }^{* *}$ Correlation is significant at the 0.01 level (2-tailed).

possible collective phrasing: Waking up in the morning is, by definition, an individual action not shared with coworkers! We changed this sentence to "when we arrive at work in the morning we feel like starting to work" since this alternative formulation does depict a shared and public moment.

\section{Results}

Table 2 summarizes the mean scores, standard deviations, correlations, Rwg $(\mathrm{j})$ 's, and ICCs for all the variables in Study 1 . Since the unit of the present analysis is the team, scores for all the measures were calculated using the weighted mean of team member responses and aggregated to the team level for statistical analysis. Using the value of .70 and above as a cut-off point (Cohen, Doveth, \& Eick, 2001) on the index of within-group interrater agreement $\left(\mathrm{Rwg}_{(\mathrm{j})}\right.$, James, Demaree, \& Wolf, 1984, 1993) the mean values are all acceptable. Intraclass Correlations (ICC1) values for job satisfaction and for most group-level variables (TWE, collective efficacy, group potency), with the exception of identification with the team and relational conflict, were between the recommended values of .05 and .20 (DeShon, Kozlowski, Schmidt, Milner, \& Wiechmann, 2004). For the individual variables (WE, burnout, subjective well-being) these values were slightly higher (around .20). This is an interesting pattern of results that can be explained theoretically: Apparently, even if within-group agreement exists on all the variables, differences in individual variables cannot be attributed to the fact of belonging to a specific group. However, and as expected, ICC(2) values were greater than ICC(1) for all variables, filling another criterion for aggregation.

\section{Individual- and Team-Level Constructs}

One of the main goals of this paper is to explore whether WE and TWE are distinguishable constructs that have significant differences between them. Correlations among the items of the individual- (UWES-9) and team-level
(TWES-9) scales suggest that individuals differentiate between the two constructs and that they are indeed measuring different things ( $r$ values between .51 and .68).

In order to test Hypothesis 1 (the aggregated mean scores on the individual WE scale and on the TWE scale will be significantly different), a mean Paired Samples $t$-test was conducted. Despite the significant mean correlation found between UWES-9 and TWES-9 $(r=.88$; $p<.001)$, these two variables do present statistically significant differences between them $(t=-3.177 ; p=.002)$. This supports our first hypothesis. Contrary to what was expected, the mean scores of the UWES-9 and TWESHM-9 (holistic measure obtained by group discussion) also correlated significantly $(r=.73 ; p=.000)$ but did not differ significantly $(t=-1.064 ; p=.292)$.

\section{Aggregated and Holistic Measure}

For testing Hypothesis 2 (no significant differences exist between measuring TWE through the aggregation of individual scores using the referent-shift model and measuring it by a holistic measure reflecting the interaction between team members), another mean Paired Samples $t$-test was conducted. Variables were significantly correlated $(r=.74 ; p<.001)$ and, more importantly, no significant differences between them were found $(t=.38 ; p=.70)$, which supports our second hypothesis. In addition, the aggregated measure demonstrated relations of greater magnitude with the majority of other variables than the group discussion method measure. Considering these results, the next set of analyses was conducted using TWES-9, and not the holistic measure.

\section{Convergent and Discriminant Validity}

Hypotheses $3 a-3 c$ are related to TWE's convergent and discriminant validity (TWE is positively correlated with: The dimension of personal accomplishment of burnout, job satisfaction, subjective well-being, identification with the team, objective performance, collective efficacy, and 
Table 3. Confirmatory factor analysis exploring the independence of TWE from related constructs $(n=55)$

\begin{tabular}{llllc}
\hline & & CFI & SRMR & $\Delta \chi^{2}$ \\
\hline TWE and group potency & 1 Factor & .726 & .1075 & $47.9(d f=1)$ \\
& 2 Factors & .845 & .0873 & $<0.0001$ \\
TWE and collective efficacy & 1 Factor & .666 & .1288 & $149.48(d f=1)$ \\
TWE and MBI-PE & 2 Factors & .866 & .0882 & $<0.0001$ \\
& 1 Factor & .753 & .1054 & $106.2(d f=1)$ \\
& 2 Factors & .822 & .0929 & $<0.0001$ \\
\hline
\end{tabular}

group potency; negatively correlated with the dimensions of emotional exhaustion and cynicism of burnout and not significantly correlated with relationship conflict). TWES9 correlated significantly with all the variables included in this study (cf. Table 2), with the exception of relational conflict, and in the expected direction. This shows that TWE is in fact related with the theoretically proposed variables. Moreover, and in what Hypothesis $3 \mathrm{~d}$ is concerned (TWE has relationships of greater magnitude with teamrelated variables, whereas WE has relationships of greater magnitude with individual-level variables) individual- and team-level work engagement have different patterns of correlations. WE shows higher correlations with subjective well-being and with the emotional exhaustion and cynicism dimensions of burnout, all individual-level variables. TWE shows higher correlations with variables that reflect team processes and emergent states (collective efficacy, group potency, and identification with the team), as well as with individual-level variables that are essentially work related: Job satisfaction and the personal effectiveness dimension with burnout. Hypothesis $3 \mathrm{~d}$ was, then, partially supported.

Considering the high correlations between TWE and the personal effectiveness dimension of burnout $(r=.69)$, group potency $(r=.63)$, and collective efficacy $(r=.61)$, we performed additional confirmatory factor analysis, as implemented by AMOS 17 (Byrne, 2010), to test whether these constructs were indeed distinct. Since TWE, group potency, and collective efficacy are referent-shift constructs, factor analyses were conducted at the team level $(N=55)$ as recommended by Chen, Mathieu, and Bliese (2004). ${ }^{1} \mathrm{Hu}$ and Bentler (1999) posit that when the sample size is smaller than 250 combinations based on CFI and SRMR are preferable, since they represent the lowest sum of Type 1 and Type 2 errors. Moreover, the CFI index is particularly recommended for model comparison purposes (Goffin, 1993). Therefore, our evaluation of the goodness of fit of the models presented in this paper will rely heavily on the CFI/SRMR combination, where $\mathrm{CFI}$ values greater than .90 and SRMR values of .08 or lower are considered a good fit. From the results presented in Table 3, we can conclude that TWE is an independent construct from the other three, providing further validity for the TWE construct: The two factor models for all variables showed a better fit. Moreover, the chi-square difference test also shows that the 1 and 2 factor solutions are significantly different from each other, with the 2 factor solution being better. Therefore, the construct of TWE is indeed distinct from (although related to) those other constructs.

\section{Factor Structure}

In order to start tackling Hypothesis 4 (the factor structure of TWE is similar to the one of individual-level work engagement and is composed by three factors: vigor, dedication, and absorption.), we analyzed the factor structure of TWES-9 and TWES-HM-9, with each of the nine items of the scale aggregated to the team level. First, an exploratory factor analysis was conducted (Principal Components method with Varimax rotation) on each scale. It revealed only one factor for both the TWES-9 $(69.75 \%$ of variance explained) and the TWES-HM-9 $(57.91 \%$ of the variance explained). Confirmatory factor analysis was afterwards used to test the fit of the two competing models for TWES-9 and TWES-HM-9.

One-factor models assume that the scale items load on one common general engagement factor and 3-factor models assume that the items load on three separate but correlated factors, namely vigor, dedication, and absorption. Considering TWES-9, the 3-factor model was not an admissible solution to fit the data (the covariance matrix is not positive definite), whereas the 1 -factor model almost reaches the cut-off criteria for the fit indexes $(\mathrm{CFI}=.87$; SRMR = .07). Modification Indexes (MI) were inspected to assess whether the fit of the model could be improved. These values revealed that the fit could be improved by allowing the errors of item 1 and item 2 (that belong to the same theoretical dimension of engagement, vigor) to correlate $(\mathrm{MI}=23.44)$. This adjustment allowed for better

1 We acknowledge our small sample size for running these CFAs. Thus, for exploratory purposes in sample 1, we also ran the factor analyses at the individual level $(N=226$ individuals). These additional analyses demonstrated that the items loaded as expected on team work engagement, collective efficacy, team potency, and the personal efficacy dimension of burnout (results available from the authors upon request). 
a fit, with both indexes reaching the respective cut-off points $(\mathrm{CFI}=.93$; SRMR $=.06$ ). With TWES-HM-9, the pattern of results is not so clear, with both models presenting CFI values above .90 and SRMR values below .08. Nonetheless, the chi-square difference test shows that these models are statistically different between them $\left(\Delta \chi^{2}=15.514 ; d f=3 ; p=.0014\right)^{2}$

\section{Discussion}

The results supported the hypothesis that TWE is a valid construct, independent of that of individual-level work engagement and that it is more than the aggregation of individual scores on the individual work engagement instrument. Indeed, the mean results of UWES-9 and TWES-9 are statistically different. This is a relevant result, not only for the study of work engagement at multiple levels, but also for the multilevel research, where no clear rule transposing individual constructs to higher levels exists at the moment, namely, concerning measurement.

Comparing with individual work engagement, the pattern of correlations for both variables shows that TWE has higher correlations with team-level variables, as expected, but also with work-related ones. This justifies the use of a team-referent measure of engagement, particularly in the actual scenario of many companies where work is team-based. Furthermore, it underlies the importance of understanding and paying attention to work teams, team functioning, and team processes, since it seems that, rather than individual states, team emergent states are related to job satisfaction and to a sense of job efficacy.

We decided to use the 9-item scale because the 1 and 3factor solutions of this scale (at the individual level) are the ones that show a relative invariance across countries (Bakker \& Schaufeli; Schaufeli et al., 2006), whereas the invariance of the 3 -factor structure of the 17-item scale is relatively poor. Analyzing the factor structure using the 9-item scale, we were unable to find an acceptable 3-factor model in the aggregated measure. Moreover, Cronbach's alpha for the total scale was very high. Possible explanations are related to our sample: It was not large and was mainly composed of students. The holistic measure, however, accepts both solutions. It seems that being able to discuss individual perceptions of TWE results in a more differentiated view of the team's energy and motivation. Nonetheless, these results must be viewed with caution, considering the small sample size.

We also intended to contribute to an understanding of the best way to measure collective constructs: Either through aggregation of individual responses on collectively formulated items or with a single holistic measure answered by the whole group after a discussion. Although the pattern of correlations of both methods with the variables chosen for assessing the construct's convergent and discriminant validity is similar, and no statistically significant differences were obtained between them - which leads us to think that both capture TWE in a similar way - two other considerations must be taken into account. First, the magnitude of the correlations with the variables chosen for assessing the construct's convergent and discriminant validity was higher for the aggregated measure. Second, no significant differences were found between the means of the holistic measure and of the aggregation of scores on the individual scale. Contrary to Gibson et al. (2000) who, for collective efficacy, concluded that the discussion method better captured the collective construct, it seems that in this case the aggregated measure is more appropriate. It is possible that having group members making judgments together is not a valid method for data collection on TWE. Bandura (1997) stated that the group discussion method is subject to group processes such as pressures for conformity and social persuasion. In addition, he argues that a group belief is better characterized by a representative value for the members' beliefs and by the degree of variability/consensus around that central belief. Moreover, for Goddard et al. (2004) the group discussion method is prone to social desirability behaviors and answers and, thus, is a less reliable one. One possible limitation of the present data collection is that we did not counterbalance the order in which teams completed both methods (aggregation vs. discussion). Since all individuals had an opportunity to form their own opinion prior to team discussion, the influence of dominant members is less likely to have had a large impact. Nonetheless, and despite giving the same instructions to all groups, we were able to observe (although not systematically) the process of filling in the holistic measure. Indeed, many of the groups had only one or two members actively discussing the items. This could partly explain why the results are closer to those of the individual scales than the aggregated collective measure and the different factor structure found with the holistic measure.

The sample used in this preliminary analysis of the factor structure of TWE was small. This may have led to unclear results about the factorial structure of the construct. Moreover, half of the data were collected from students using the general engagement scale and not the specific student's one - with the main difference being the wording of the items (from "work" to "study") and the study was cross-sectional. Also, validation of TWE was still lacking empirical evidence for the discriminant validity between team engagement and similar constructs, such as team viability and team performance. Therefore, and since the results were not totally consistent with the theoretical three-dimensional definition of work engagement, we decided to conduct a second study to analyze the factorial structure more profoundly.

2 Again, factor analyses were also run at the individual level $(N=226$ individuals). These analyses of TWES9 also resulted in a better fit of the 1 -factor model, with the covariance matrix of the 3 -factor solution being "not positive definite" (results available from the authors upon request). 


\section{Study 2}

\section{Method}

\section{Participants, Procedure, and Measures}

The sample for this second study was composed of participants of the "Global Management Challenge ${ }^{\circledR}$ ", $\left(\mathrm{GMC}^{\circledR}\right)$, a management simulation developed by a company specialized in the development of business simulations that has been used for more than 30 years. During a 5-week period, participants must manage a virtual company and decide on investment choices and other managerial issues. Participants were emailed a questionnaire with the TWE scale during the last week of the competition in order to collect data for the present study. Participants were 799 individuals, organized in 175 teams. The average team size was 4.67 members $(S D=.61)$. The participants' average age was 28.81 years $(S D=8.4$ years $)$ and $67.8 \%$ were men. Teams were composed of students $(40.3 \%)$, full-time workers in different companies $(42.4 \%)$, and mixed, with both students and full-time workers $(17.3 \%)$. The measures for this study can be found in Table 1 . In Table 4 we present the descriptive statistics, the $\operatorname{Rwg}_{(\mathrm{j})}$ and ICCs measures and the correlations between the variables.

\section{Results}

\section{Further Analysis on Convergent and Discriminant Validity}

In order to show further evidence for the existence of TWE as an independent construct, we analyzed the correlations between TWE and team viability $(r=.27 ; p<.005)$ and TWE and objective team performance $(r=.17 ; p<.05)$. Considering these results, TWE can be considered a different, independent variable from these other two. Taken together the results from Study 1 and 2, Hypotheses 3a, $3 \mathrm{~b}$, and $3 \mathrm{c}$ were supported.

\section{Factor Structure of TWE}

To test our 4th hypothesis (the factor structure of TWE is similar to the one of individual-level work engagement and is composed by three factors: vigor, dedication, and absorption), we conducted a confirmatory factor analyses (CFA) using the maximum likelihood estimation method and AMOS 17 software, testing two models (1-factor model and 3-factor model) at the team level. In order to do so, we aggregated each of the nine items of the scale to the team level and conducted the CFA (Chen et al., 2004). With this sample ( $n=175$ teams), the fit indexes used to access the model fit were not clear in undoubtedly defining a best fitting model, when no constraints were established (cf. Model 1, Table 5). When inspecting the modification indexes for both the 1- and the 3-factor models, we observed that the model fit could be improved by allowing the errors of item 8 and item 9 (both belonging to the absorption dimension, theoretically) and errors 1 and 2 (both belonging to the vigor dimension of engagement, theoretically) to correlate. With one (errors 8 and 9) or both constraints added to the model (Models 2 and 3 in Table 5, respectively), the 3 -factor model became an unacceptable solution (the covariance matrix is not positive definite), whereas the 1-factor model's fit was improved (Model 3: CFI = .97; SRMR = .01; Model 4: CFI = .98; SRMR $=.01)$.

Table 4. Means, standard deviations, correlations, rwgs, and ICCs for all the variables in the study

\begin{tabular}{lccccccc}
\hline & rwg & ICC1 & ICC2 & M & $S D$ & 1 & 2 \\
\hline 1.TWES9 & .75 & .15 & .49 & 5.5 & .88 & 1 & $.27^{* *}$ \\
2. Viability & .81 & .11 & .42 & 4.2 & .54 & $.17^{*}$ \\
3. Obj. performance & - & - & - & .06 & .20 & .08 \\
\hline
\end{tabular}

Notes. ${ }^{*}$ Correlation is significant at the 0.05 level (2-tailed); ${ }^{* *}=$ Correlation is significant at the 0.01 level (2-tailed).

Table 5. CFAs for exploring TWE's factor structure

\begin{tabular}{|c|c|c|c|c|c|c|c|c|c|c|}
\hline & & $\chi^{2} / d f$ & GFI & AGFI & RMSEA & NFI & NNFI & CFI & SRMR & AIC \\
\hline \multirow[t]{2}{*}{ Model 1} & $1 \mathrm{~F}$ & 5.669 & .850 & .750 & .164 & .951 & .946 & .959 & .0149 & 189.064 \\
\hline & $3 \mathrm{~F}$ & 6.2000 & .852 & .722 & .173 & .953 & .940 & .960 & .0143 & 190.800 \\
\hline \multirow[t]{2}{*}{ Model 2} & $1 \mathrm{~F}$ & 4.551 & .868 & .771 & .143 & .962 & .959 & .970 & .0112 & 156.331 \\
\hline & $3 \mathrm{~F}$ & \multicolumn{9}{|c|}{ Cov. matrix not positive definite } \\
\hline \multirow[t]{2}{*}{ Model 3} & $1 \mathrm{~F}$ & 3.708 & .899 & .818 & .125 & .970 & .969 & .978 & .0107 & 132.705 \\
\hline & $3 \mathrm{~F}$ & \multicolumn{9}{|c|}{ Cov. matrix not positive definite } \\
\hline
\end{tabular}




\section{Discussion}

The results of the CFA conducted in Study 2 reinforced the idea that TWE has a unifactorial structure. This did not support our theory-driven hypothesis of a tridimensional structure of the construct.

At the individual level, similar results have been found in Japan (Shimazu et al., 2008) and Germany (Sonnentag, 2006). One possible explanation can be the high correlation of the three theoretically acceptable components of engagement. One can also argue that, at the team level, work engagement is a more global and unitary construct. Assuming differences in structure between individual-and teamlevel constructs, TWE arises from the interaction between team members and, therefore, individuals must have some kind of observable behavior in order to allow others to perceive their affective-motivational state. Going from the awareness of an individual internal state to the awareness of a more complex shared state may, thus, imply an inverse pattern of individual perception: From a more complex and multifaceted perception of how one is feeling (since individuals do experience different and almost simultaneous moods and thoughts) to a more holistic and broader perception of how a group of others is feeling, based on observable cues. Moreover, this difference in factor structure may also be interpreted in terms of composition process of the team construct: Changing the referent results in a construct that is different, although derived from, its original form. Consistent with these findings, future studies should examine alternative and parsimonious ways of measuring TWE, in line with a solid theoretical referent.

\section{Conclusion and Future Directions}

Taken together, the results from all of the analyses show that the two scales (individual- and team-level) measure two different constructs. TWE seems to be a promising construct for future research on the affective and motivational emergent states of work teams. The studies presented have, however, some limitations. One of them, already mentioned, is the possible confounding effect of not having counter-balanced the order in which participants filled the aggregated measure and the group discussion one in Study 1 .

In what practical implications are concerned, the results presented have two main contributions. On the one hand, they show the importance of having specific, team-referent measures when studying team-level constructs and the danger it may be to assume that aggregating individual-referent items accurately represents a collective construct. On the other hand, they illustrate that teams have specific dynamics and that promoting motivation and well-being in individuals within teams may call for different actions than motivating isolated employees. Managers and team leaders from all the types of organizations want to work with energetic, motivated, and focused teams in order to achieve the goals of the organization and to fulfill its mission. A further understanding of the mechanisms underlying TWE will hand practitioners over new sets of possible tools to successfully apprehend and deal with that relevant issue. Therefore, given the importance of teams and team efficacy in the work environment nowadays and after validating the existence of the construct at the team level, it is now important to reflect upon its function and structure. Future studies are needed to test the functional equivalence between the construct at different levels, and to provide additional support for the adequacy of the present operationalization. Future work should, therefore, aim at understanding the relationships of TWE and team effectiveness and how the construct develops and unfolds overtime: How does TWE emerge in the team? What team processes and dynamics is it related to? Are some individuals in the team more responsible for its development?

The door is open for an exciting research agenda.

\section{References}

Bakker, A. B., \& Demerouti, E. (2007). The job demandsresources model: State of the art. Journal of Managerial Psychology, 22, 309-328. doi: 10.1108/0268394071 0733115

Bakker, A. B., \& Leiter, M. P. (2010). Work engagement: A handbook of essential theory and research. Hove, UK: Psychology Press.

Bakker, A. B., van Emmerik, H., \& Euwema, M. C. (2006). Crossover of burnout and engagement on work teams. Work and Occupations, 33, 464-489. doi: 10.1177/073088840 6291310

Bandura, A. (1997). Self-efficacy: The exercise of control. New York, NY: Freeman.

Bar-Tal, D. (1990). Group beliefs: A conception for analyzing group structure, processes, and behavior. New York, NY: Springer-Verlag.

Bell, S. T., \& Marentette, B. J. (2011). Team viability for longterm and ongoing organizational teams. Organizational Psychology Review, 1, 275-292. doi: 10.1177/204138661 1405876

Byrne, B. M. (2010). Structural equation modeling with AMOS: Basic concepts, applications and programming (2nd ed.). New York, NY: Routledge.

Chan, D. (1998). Functional relations among constructs in the same content domain at different levels of analysis: A typology of composition models. Journal of Applied Psychology, 83, 234-246. doi: 10.1037/0021-9010.83.2.234

Chen, G., Bliese, P. D., \& Mathieu, J. E. (2005). Conceptual framework and statistical procedures for delineating and testing multilevel theories of homology. Organization Research Methods, 8, 375-409. doi: 10.1177/109442810 5280056

Chen, G., Mathieu, J. E., \& Bliese, P. D. (2004). A framework for conducting multilevel construct validation. In F. Dansereau \& F. Yamarino (Eds.), Multi-level issues in organizational behavior and processes (Vol. 3, pp. 273-303). Oxford, UK: Elsevier Science.

Cintra, L., \& Cunha, C. (1984). Nova gramática do português contemporâneo [New grammar of contemporary Portuguese]. Lisbon, Portugal: Edições João Sá da Costa.

Cohen, A., Doveth, E., \& Eick, U. (2001). Statistical properties of the rwg $(J)$ index of agreement. Psychological Methods, 6, 297-310. doi: 10.1037/1082-989X.6.3.297

Costa, P. L., Passos, A. M., \& Bakker, A. B. (2012). Team work engagement: Considering team dynamics for engagement 
[working paper]. Lisbon, Portugal: ISCTE-IUL, Business Research Unit (BRU-IUL).

De Dreu, C. K. W., \& Weingart, L. R. (2003). Task versus relationship conflict, team member satisfaction, and team effectiveness: A meta-analysis. Journal of Applied Psychology, 88, 741-749. doi: 10.1037/0021-9010.88.4.741

DeShon, R. P., Kozlowski, S. W. J., Schmidt, A. M., Milner, K. R., \& Wiechmann, D. (2004). A multiple goal multilevel model of feedback effects on the regulation of individual and team performance in training. Journal of Applied Psychology, 89, 1035-1056. doi: 10.1037/0021-9010.89. 6.1035

Diener, E. (1994). Assessing subjective well-being: Progress and opportunities. Social Indicators Research, 31, 103-157.

Diener, E., Emmons, R., Larsen, J., \& Griffin, S. (1985). The satisfaction with life scale. Journal of Personality Assessment, 49, 71-75. doi: 10.1207/s15327752jpa4901_13

Doosje, B., Ellemers, N., \& Spears, R. (1995). Perceived intragroup variability as a function of group status and identification. Journal of Experimental Social Psychology, 31, 410-436. doi: org/10.1006/jesp.1995

Fredrickson, B. L. (2001). The role of positive emotions in positive psychology: The broaden-and-build theory of positive emotions. American Psychologist, 56, 218-226. doi: 10.1037/0003-066X.56.3.218

Gibson, C. B., Randel, A. E., \& Earley, P. C. (2000). Understanding group efficacy; an empirical test of multiple assessment methods. Group and Organizational Management, 25, 67-97. doi: 10.1177/1059601100251005

Goddard, R. D., Hoy, W. K., \& Hoy, A. W. (2004). Collective efficacy beliefs: Theoretical developments, empirical evidence, and future directions. Educational Researcher, 33, 3-13. doi: 10.3102/0013189X033003003

Goffin, R. D. (1993). A comparison of two new indices for the assessment of fit of structural equation models. Multivariate Behavioral Research, 28, 205-214. doi: 10.1207/ s15327906mbr2802_3

Guzzo, R. A., Yost, P. R., Campbell, R. J., \& Shea, G. P. (1993). Potency in groups: Articulating a construct. British Journal of Social Psychology, 32, 87-106. doi: 10.1111/ j.2044-8309.1993.tb00987.x

Halbesleben, J. R. B. (2010). A meta-analysis of work engagement: Relationship with burnout, demands, resources and consequences. In A. B. Bakker \& M. P. Leiter (Eds.), Work Engagement: A handbook of essential theory and research (pp. 10-24). Hove, UK: Psychology Press.

Halbesleben, J. R. B., \& Wheeler, A. R. (2008). The relative roles of engagement and embeddedness in predicting job performance and intention to leave. Work and Stress, 22, 242-256. doi: 10.1080/02678370802383962

Hatfield, E., Cacioppo, J., \& Rapson, R. L. (1994). Emotional contagion. New York, NY: Cambridge University Press.

Hu, L., \& Bentler, P. M. (1999). Cutoff criteria for fit indexes in covariance structure analysis: Conventional criteria versus new alternatives. Structural Equation Modeling, 6, 1-55. doi: 10.1080/10705519909540118

James, L. R., Demaree, R. G., \& Wolf, G. (1984). Estimating within-group interrater reliability with and without response bias. Journal of Applied Psychology, 69, 85-88.

James, L. R., Demaree, R. G., \& Wolf, G. (1993). rwg: An assessment of within-group interrater agreement. Journal of Applied Psychology, 78, 306-309.

Jehn, K. A., \& Mannix, E. A. (2001). The dynamic nature of conflict: A longitudinal study of intragroup conflict and group performance. Academy of Management Journal, 44, 238-251. doi: $10.2307 / 3069453$

Jex, S. M., \& Bliese, P. D. (1999). Efficacy beliefs as a moderator of the impact of work-related stressors: A multi-level study. Journal of Applied Psychology, 84, 349-361. doi: 10.1037/0021-9010.84.3.349

Locke, E. A. (1976). The nature and causes of job satisfaction. In M. D. Dunnette (Ed.), Handbook of industrial and organizational psychology (pp. 1 297-1349). Chicago IL: Rand McNally.

Marks, M. A., Mathieu, J. A., \& Zaccaro, S. J. (2001). A temporally based framework and taxonomy of team process. Academy of Management Review, 26, 356-376.

Maslach, C. (1999). A multidimensional theory of burnout. In C. L. Cooper (Ed.), Theories of occupational stress. Oxford, UK: Oxford University Press.

Maslach, C., Jackson, S. E., \& Leiter, M. P. (1996). The Maslach burnout inventory (3rd ed.). Palo Alto, CA: Consulting Psychologists Press.

Riordan, C. M., \& Weatherly, E. W. (1999). Defining and measuring employees' identification with their work groups. Educational and Psychological Measurement, 59, 310-324. doi: 10.1177/00131649921969866

Salanova, M., Llorens, S., Cifre, E., Martinez, I. M., \& Schaufeli, W. B (2003). Perceived collective efficacy, subjective well-being and task performance among electronic work groups: An experimental study. Small Group Research, 34, 43-73. doi: 10.1177/1046496402239577

Schaufeli, W. B., \& Bakker, A. B. (2003). Utrecht work engagement scale: Preliminary manual, Version 1. Utrecht, The Netherlands: Occupational Health Psychology Unit, Utrecht University.

Schaufeli, W. B., Bakker, A. B., \& Salanova, M. (2006). The measurement of work engagement with a short questionnaire: A cross-national study. Educational and Psychological Measurement, 66, 701-716. doi: 10.1177/001316440 5282471

Schaufeli, W. B., Salanova, M., González-Romá, V., \& Bakker, A. B. (2002). The measurement of engagement and burnout: A two sample confirmatory actor analytic approach. Journal of Happiness Studies, 3, 71-92.

Shimazu, A., Schaufeli, W. B., Suzuki, A, Kosugi, S., Nashiwa, H., Kato, A., ... Goto, R. (2008). Work engagement in Japan: Validation of the Japanese version of the Utrecht work engagement scale. Applied Psychology: An International Review, 57, 510-523. doi: 10.1111/j.1464-0597.2008. 00333.x

Sonnentag, S. (2006). Recovery, work engagement, and proactive behavior: A new look at the interface between nonwork and work. Journal of Applied Psychology, 88, 518-528. doi: 10.1037/0021-9010.88.3.518

Stajkovic, A. D., Lee, D., \& Nyberg, A. J. (2009). Collective efficacy, group potency, and group performance: Metaanalyses of their relationships, and test of mediation model. Journal of Applied Psychology, 94, 814-828. doi: 10.1037/ $\mathrm{a} 0015659$

Standifer, R. L., Halbesleben, J., \& Kramer, J. (2009, April). The impact of individual temporal differences on team process and team effectiveness Paper presented at the 24th annual conference of the society for industrial \& organizational psychology (SIOP), New Orleans, LA.

Tajfel, H., \& Turner, J. C. (1986). The social identity theory of intergroup behaviour. In S. Worchel \& W. G. Austin (Eds.), Psychology of intergroup relations (pp. 7-24). Chicago, IL: Nelson-Hall.

Torrente, P., Salanova, M., Llorens, S., \& Schaufeli, W. B. (2012a). From "I" to "We": The factorial validity of a team work engagement scale. In J. Neves \& S. P. Gonçalves (Eds.), Occupational health psychology: From burnout to well-being. Lisbon, Portugal: Edições Sílabo.

Torrente, P., Salanova, M., Llorens, S., \& Schaufeli, W. B. (2012b). Teams make it work: How team work engagement 
mediates between social resources and performance in teams. Psicothema, 24, 106-112.

Totterdel, P., Kellett, S., Teuchmann, K., \& Briner, R. B. (1998). Evidence of mood linkage in work groups. Journal of Personality and Social Psychology, 8, 672-682. doi: 10.1037//0022-3514.74.6.1504
Patrícia Costa

Instituto Universitário de Lisboa - ISCTE-IUL

Centro de Investigação de Intervenção Social

Av. das Forças Armadas

Lisbon, 1649-026

Portugal

Tel. +351916 373351

Fax +351210464174

E-mail patricia.lopes.costa@gmail.com

\section{Appendix}

\section{Proposed TWES-9 Items}

\begin{tabular}{|c|c|c|c|}
\hline $\begin{array}{l}\text { No. from the } \\
\text { original scale }\end{array}$ & Dimension & Original UWES & Proposed Team Work Engagement Scale \\
\hline 1 & Vigor & $\begin{array}{l}\text { At my work, I feel that } \\
\text { I am bursting with energy }\end{array}$ & At our work, we feel bursting with energy \\
\hline 4 & Vigor & At my job, I feel strong and vigorous & At our job, we feel strong and vigorous \\
\hline 5 & Dedication & I am enthusiastic about my job & We are enthusiastic about our job \\
\hline 7 & Dedication & My job inspires me & Our job inspires us \\
\hline 8 & Vigor & $\begin{array}{l}\text { When I get up in the morning, } \\
\text { I feel like going to work }\end{array}$ & $\begin{array}{l}\text { When we arrive at work in the morning, } \\
\text { we feel like starting to work }\end{array}$ \\
\hline 9 & Absorption & I feel happy when I am working intensely & We feel happy when we are working intensely \\
\hline 10 & Dedication & I am proud of the work that I do & We are proud of the work that we do \\
\hline 11 & Absorption & I am immersed in my work & We are immersed in our work \\
\hline 14 & Absorption & I get carried away when I am working & We get carried away when we are working \\
\hline
\end{tabular}

